\title{
TOWARDS UNDERSTANDING OF WORKPLACE CONFLICT: AN EXAMINATION INTO CAUSES AND CONFLICT MANAGEMENT STRATEGIES
}

\author{
Dana Egerová, Lucie Rotenbornová \\ University of West Bohemia in Pilsen, Czech Republic \\ E-mail: egerova@kpm.zcu.cz, rotenbor@kpm.zcu.cz
}

\begin{abstract}
Workplace conflict is regarded as a naturally and unavoidably occurring phenomenon in today's organisations. To identify the causes of workplace conflict it is critically important to determine appropriate conflict management strategies and effectively manage conflict. The purpose of this study was to explore causes of interpersonal conflicts between managers and employees and the conflict management styles used to handle these conflicts. A qualitative approach including thematic analysis and content analysis was employed. The thematic analysis was carried out to explore the themes concerning causes of conflicts between managers and employees. The content analysis was used to identify the conflict management styles. The data for both analyses included 47 individual written assignments describing conflict situations between managers and employees. Four general themes including poor management, manager personality, poor communication and differences in views emerged from the thematic analysis. Each theme also encompassed a number of subthemes. The findings of the content analysis showed that fight was the most adopted style used by both male and female managers. The findings also revealed that three styles emerge as the most frequently adopted by employees including avoidance, adaptation, and collaboration. The practical implications and limitations of this study are discussed.
\end{abstract}

Keywords: causes of conflict, conflict management styles, gender, qualitative analysis, workplace conflict

\section{Introduction}

Continued changes in economic, social and technological environments at both the global and local level have increased the uncertainty of the environments in which organisations today have to operate. Consequently, this uncertainty has created the potential for workplace conflict. Workplace conflict can occur between employees, an employee and a manager or between groups, in all functional areas in an organisation as much as at different levels of the organisation (De Dreu, 2011; Gadegaardet et al., 2018). Conflicts may arise from misunderstandings about how a task or a job should be done, or the content of the task (Tjosvold, 2008; Wright et al., 2017).

It is accepted that conflict in an organisation and the style of conflict management implemented significantly influence individual, group, and organisational effectiveness (Choi, 2013). The presence of conflict can have both negative and positive consequences for individuals and organisations (Rahim et al., 2000). On the one hand, moderate levels of workplace conflict promote growth, stimulate discussion and knowledge-sharing, enabling groups to innovate and make better decisions (Lu et al., 2011). Well-managed conflict demonstrates a healthy and dynamic organisational culture conductive to effective working (Danielsson et al., 2015).

On the other hand, workplace conflict is a prevalent workplace problem associated with severe adverse implications on employees (e.g., lowered job motivation, absenteeism, 
Dana EGEROVÁ, Lucie ROTENBORNOVÁ. Towards understanding of workplace conflict: An examination into causes and conflict management strategies

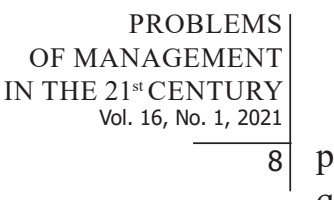

chological distress, anxiety, and frustrations) and organisations (e.g., decrease in work quality, decline in performance turnover, reduced productivity) (Wright et al., 2017). According to Riaz and Junaid (2012) badly managed workplace conflict causes stress, produces anxiety and frustrations, and results in lowered job motivation, humiliation and physical illness.

In order to mitigate the negative effects of conflict, the causes of the conflict should be identified. In this regard, some authors (Van Tonder et al., 2008) have argued that understanding and identification of the causes of conflict in an organisation is critically important to determine appropriate conflict resolution strategies and to effectively manage conflict.

There are numerous studies examining the workplace causes (Zia, \&, Syed, 2013; Khan et al., 2016) and conflict management styles (Chan et al., 2014; Tabassi et al., 2017). Some studies have also been examining the effects of gender on conflict management styles (Brewer et al., 2002; Rahim, \& Katz, 2019). However, the results of empirical studies on these issues remain mixed. Thus, this study aims to explore the perceived causes of workplace conflicts and conflict management styles used by managers, specifically in the context of Czech organisations. The gender perspective has also been applied in the present study.

\section{Theoretical Framework}

\section{Workplace Conflict}

Conflict is a natural outcome of human interaction as people are different from each other. Therefore, in workplace settings where two or more employees interact with each other conflict is regarded as a common and unavoidable phenomenon (Danielsson et al., 2015; Khan 2016). As noted by Rahim et al. (2000) conflict arises when an individual perceives that his or her goals, attitudes, values, or feelings are different from those of another individual. In addition, Avgar (2020) noted that conflict in the workplace is a product of decisions, activities, processes, and practices across the organisation that occur among different stakeholders.

Although organisational literature on conflict provides numerous definitions of conflict (sometimes contradictory) there is currently no agreement on the definition of workplace conflict (Tjosvold, 2008). Conflict has been defined as a state when one party considers something important, and the other party disagrees. (Doucet et al., 2009). Likewise, Omisore and Abiodun (2014) understand conflict as a process in which the interests of one party are being opposed by another party.

Rahim (2002) pointed out that workplace conflict differs from other conflicts because employees have to work together in order to achieve organisational goals. In this regard, Danielsson et al. (2015) noted that conflict arises in situations where individuals, groups, or organisations are trying to achieve their objectives, and these are inconsistent with one another. Conflicts may be understood also as disagreements about the right treatment or the right way to perform work, as a struggle between employees over values, power, or scarce resources (Moore, 1986; Gadegaard et al., 2018). According to Cheng and McCarthy (2013) employees' engagement in many divergent roles in the workplace that come with different responsibilities and challenges also leads to work-life conflict.

There are different types of workplace conflict. One of the most established typologies distinguishes between task-related conflict, relationship conflict, and process-related conflicts (Jehn, 1997). Task-related conflict focuses on the content, and usually occurs when there are disagreements or different ideas regarding task issues, including goals, content decisions and areas. Relationship conflict focuses on interpersonal relationships and usually occurs when individuals have an interpersonal dispute with negative feelings between one another. Causes of relationship conflict may be for example individual differences such as gender, race, age, and functional background (Jehn, 1997; Lee et al., 2015). Task-related conflict tends to have 
a positive impact on collaboration and performance, while relationship conflict and processrelated conflict have negative impacts on collaboration and performance (Pelled et al., 1999).

PROBLEMS

OF MANAGEMENT

IN THE $21^{\text {st }}$ CENTURY

Vol. 16 , No. 1, 2021

Gostin et al. (2012) have classified workplace conflicts as horizontal conflicts that arise between individuals or departments working under the same hierarchical level and vertical conflicts that arise between individuals or departments on different hierarchical levels.

Organisational conflict may also be classified as intrapersonal (intra-personal level), interpersonal (two or more person), intragroup (within a work group), intergroup (between two or more work groups) and interorganisational (between two or more organisations) (Rahim \& Bonoma, 1979; Rahim, 1985).

This study focuses on interpersonal conflicts with managers or co-workers, defined as a "phenomenon that occurs between interdependent parties as they experience negative emotional reactions to perceived disagreements and interference with the attainment of their goals." (Barki, \& Hartwick, 2001, p. 198).

\section{Causes of Workplace Conflict}

There are many sources in the work environment which may play a role in the rise of interpersonal conflict. Cappozoli (1995) proposed the following sources of workplace conflict: culturally diverse values, different attitudes, different goals, different needs that are not met, various expectations of how the process will work and what the outcomes will be, different perceptions of a situation or problem, different interpretations of the same information, limited resources, different personalities, or different interests. Job performance, unrealistic demands, lack of resources and constraints on employees also lead to interpersonal conflicts (Patton, 2018).

According to Rahim and Bonoma (1979) sources of conflict may be classified as personalcultural and organisational. Personal-cultural sources include differences in personalities such as differences in attitudes, values, beliefs, skills, etc., and cultural backgrounds between organisational participants. Organisational sources refer to differentiated systems, rules and procedures, the hierarchy of authority, etc., in an organisation, and the mechanism for integration.

De Raeve et al. (2008) suggested five domains of interpersonal conflict: job content (job requirements, job tasks, decision latitude, responsibilities), work conditions (physical demands of the work), work relations (social support, manager and colleagues), terms of employment (work schedule, overtime, autonomy with respect to workplace, workhours, holidays, leaving the workplace, and taking breaks), and the evaluation of work (job satisfaction, balance between achievements and rewards, consideration of effort, respect for work).

An empirical investigation of sources was undertaken by Khan et al. (2016), who found in their study the most important causes of conflict between employees to be differences in goals and job tasks, negative perception and poor communication concerning unclearly defined job tasks and duties. In addition, Zia and Syed (2013) identified in their study the following five major causes: performing extra duties and workload allocations, ridiculing co-workers, variation in salary, miscommunication and limited resources.

As noted above, interpersonal conflict in the workplace is influenced by a variable set of causes. Furthermore, as stated by Khan et al. (2016) causes can vary according to the situation within an organisation.

\section{Conflict Management Styles}

There are several different strategies which can be applied to handle conflicts. These strategies are based on the work of Blake and Mouton (1964). According to their work, there are five conflict management styles: forcing, withdrawing, smoothing, compromising and 
Dana EGEROVÁ, Lucie ROTENBORNOVÁ. Towards understanding of workplace conflict: An examination into causes and conflict management strategies

OF MANAGEMENT IN THE $21^{\text {st }}$ CENTURY Vol. 16, No. 1,2021

confrontation. This concept was revaluated by Thomas (1976) who arranged two dimensions cooperativeness and assertiveness. Chan et al. (2014) described in their study the following management styles: integrating, obliging, dominating, avoiding, and compromising. Madalina (2016) used another variant of Blake and Mouton's grid. It includes avoidance, fight, adaptation, collaboration, and compromise.

Fight is a model built on a high degree of assertiveness and low degree of cooperation. This model is used in situations where urgent action is necessary. Managers who use this method must have skills in argumentation and debate, exploitation of rank, and must keep calm and express themselves clearly (Madalina, 2016).

Avoidance is characterized by a low degree of cooperation and assertiveness. The fear of conflict and tense situations make people choose avoidance. This model might be used when a manager is dealing with a minor conflict situation (Madalina, 2016). This approach is seen as the least effective and has been called "lose-lose" (Kay \& Skarlicky, 2020).

Adaptation is characterized by low assertiveness and high cooperation (Madalina, 2016). The management of conflicts by compromise is based on a moderate level of assertiveness and cooperation. This style is usually described as a lose-win style (Rahim \& Katz, 2019). Compromise might be accepted when people involved in conflict are on a similar level of hierarchy. Compromise is used as a temporary solution. (Madalina, 2016)

Collaboration involves a high level of assertiveness and cooperation. Using this style leads to the best solution to manage conflict (Kay \& Skarlicky, 2020). The best solution to conflict is not generated by a single person but rather involves opinions and ideas of all members. (Madalina, 2016).

Studies on the conflict management styles point out that the conflict management style that individuals are likely to choose differs across national cultures (Van der Zee \& Hofhuis, 2018). For example, the study of Kim et al. (2007) has shown that Koreans, compared with the Chinese and Japanese, were more likely to use the compromise style. Similarly, Chan et al. (2008) found in their study that in a large power distance cultures become more acceptable uncooperative conflict management styles in contrast to a low power distance cultures where people tend to use the cooperative conflict management style.

Another issue that needs to be considered is the possible effect of gender on the strategies for handling conflict. Rahim and Katz (2019) argue that the use of conflict management styles has occurred differentially by gender. Brewer et al. (2002) demonstrated that masculine individuals were more associated with a dominate conflict management style whereas feminine individuals with avoiding conflict management style. On the other hand, (Caputo et al., 2018) found in their study no significant relationship between masculinity, avoiding and forcing styles.

\section{Research Questions}

Based on the prior research literature the following research questions were formulated: RQ1: What causes conflict between managers and employees?

RQ2: What conflict management styles are used by managers to handle conflict with employees?

RQ3: Do conflict management styles differ by gender?

\section{Research Methodology}

\section{General Background}

In order to answer the research questions, the qualitative approach incorporating thematic analysis and content analysis was undertaken. The thematic analysis was carried out with the 
aim of exploring the themes concerning causes of conflict between managers and employees (RQ 1). The content analysis was used to identify the conflict management styles used to handle

PROBLEMS OF MANAGEMENT IN THE $21^{\text {st }}$ CENTURY Vol. 16 , No. 1,2021 this type of conflict (RQ2) and to determine which style is preferred by different genders (RQ3).

Thematic analysis is the process of identifying and reporting themes within qualitative data (Delahunt \& Maguire, 2017). According to Braun and Clarke (2006) thematic analysis involves searching across data to find repeated patterns of meaning. This means that in thematic analysis the data are basically reviewed, organised, and summarised instead of analysed. The key concept and the main output of thematic analysis is the theme. The theme includes something important or significant about the data in relation to the research question (Delahunt \& Maguire, 2017) In the present study the themes were identified in an inductive way. The framework approach proposed by Braun and Clarke (2006) with the following six phases was followed. Phase 1) familiarizing with the data, Phase 2) generating initial codes, Phase 3) searching for themes, Phase 4) reviewing themes, and Phase 5) defining and naming themes.

Content analysis is a research method used to analyse text data (Hsieh \& Shannon, 2005). The goal of content analysis is to identify words or phrases that are frequently used in texts based on a set of coding choices (Barrett et al., 2011). According to Cavanagh (1997), content analysis allows testing of theoretical issues to enhance understanding of the data. Three distinct approaches, conventional, directed, and summative, can be applied in qualitative content analysis. The major differences between these approaches are the coding schemes and origins of the codes (Hsieh \& Shannon, 2005). In conventional content analysis, coding categories are derived directly from the text data. With a directed content approach, analysis of data starts with existing theory or previous research findings as guidance for developing the initial codes. Summative content analysis involves counting and comparisons of individual words or content, which is further taken for interpretation in relation to particular content (Hsieh \& Shannon, 2005). However, a summative approach to qualitative content analysis goes beyond word counts to include a detailed interpretation in order to discover underlying meanings of the words or the content. In this study, summative content analysis was used to investigate the usage of approaches of managers towards handling conflict.

\section{Data Analysis}

The data for both the thematic and content analysis included 47 individual written assignments describing conflict situations between employees and managers. The conflict cases were submitted by part-time students of the bachelor programme Economics and management who have at least three years' work experience. The students were asked to describe a conflict with a manager in which they were involved. The students were also asked to identify the way in which the conflict was managed. All data sets received an alphanumeric code to ensure anonymity.

The thematic analysis evolved five phases. In phase one the written assignments were repeatedly read to become familiar with the data and also to gain an overall understanding of them. In phase two the pieces of text (data extracts) were systematically coded and collated. Only the text segments relevant to the research question were coded. Coding was performed manually. The aim of the initial coding process was to label the topics mentioned. The process of initial coding resulted in a list of 87 initial codes. In phase three the codes were analysed and sorted into themes and sub-themes. At this stage 6 themes and 11 subthemes were identified. In phase four the themes and sub-themes were reviewed once more. The following 4 apparently separate themes, Poor management, Poor delegation, Leadership style and Manager personality, became forms of the two themes such as Poor management and Manager personality. 4 separate sub-themes, Work time pressure, Additional demands, Unfair treatment, and Favouritism were also integrated into the following broader sub-themes, Unfair treatment, and Work pressure. In phase four themes and sub-themes were clearly defined. 
Dana EGEROVÁ, Lucie ROTENBORNOVÁ. Towards understanding of workplace conflict: An examination into causes and conflict management strategies

PROBLEMS

OF MANAGEMENT

IN THE $21^{\text {st }}$ CENTURY Vol. 16, No. 1, 202

The content analysis process began with reading all the data repeatedly to obtain a sense of the whole context. Then, the data/words or phrases from the text that captured key concepts /styles were identified and highlighted. The data were categorised into one of the five management styles: avoidance, fight, adaptation, collaboration and compromise, and the analysis was made with the use of Excel. The coding scheme in the Excel spread sheet included five columns (number of cases, type of management style, employee, manager, gender). After analysis, quantification of the data was done to obtain descriptive frequencies of the identified themes/management styles. Finally, interpretations of the findings were performed.

\section{Research Results}

Based on thematic analysis four general themes related to the causes of conflict between managers and employees were identified as follows: (1) Poor management, (2) Manager personality, (3) Poor communication and (4) Differences in views. The first theme focuses on the aspect of managerial qualities of the manager, the second theme includes the personal qualities of the manager, the third emphasises the characteristics of communication and the four includes issues such as disagreement, differences, and misunderstandings. Each of these themes is composed of various sub-themes; for example, the theme Poor management includes three similar sub-themes, poor planning and organisation, work pressure and poor delegation. These sub-themes present the content of the main theme through their content. Similarly, the theme Manager personality's sub-themes include difficult behaviour, unfair treatment, and authoritarian manager, which describe the characteristics of the main theme. The themes and sub-themes, as well as examples of explanations, are summarized in Table 1.

Table 1

Themes and Sub-themes

\begin{tabular}{|c|c|c|}
\hline Theme & Sub-theme & Explanation - example \\
\hline \multirow[t]{3}{*}{ Poor management } & $\begin{array}{l}\text { Poor planning and organis- } \\
\text { ing }\end{array}$ & $\begin{array}{l}\text { unbalanced shift distribution, giving unreasonable tasks } \\
\text { and demands, doing unnecessary work, higher workload as } \\
\text { compared to co-workers }\end{array}$ \\
\hline & Work pressure & $\begin{array}{l}\text { working under tight deadlines, high workloads, insisting on } \\
\text { producing more work and on working faster, requirements to } \\
\text { perform a task beyond the regular schedule }\end{array}$ \\
\hline & Poor delegation & $\begin{array}{l}\text { not considering employee capacity, giving assignments } \\
\text { although the employee does not have the necessary skills, } \\
\text { overworking, one employee comparing with the other }\end{array}$ \\
\hline \multirow[t]{3}{*}{ Manager personality } & Difficult behaviour & $\begin{array}{l}\text { ironic remarks from manager, overly critical manager, failing } \\
\text { to accept different ideas, shouting at employee in front of co- } \\
\text { workers, responding with sarcasm }\end{array}$ \\
\hline & Unfair treatment & $\begin{array}{l}\text { giving favourites better schedules and assessments, granting } \\
\text { exemptions only to selected employees, promises giving by } \\
\text { manager broken, ambiguity of rules, unreceived performance } \\
\text { increment }\end{array}$ \\
\hline & Authoritarian manager & $\begin{array}{l}\text { low decision latitude, lack of independence for experienced } \\
\text { employee, no space to do task differently, lack of trust in } \\
\text { employee }\end{array}$ \\
\hline \multirow[t]{2}{*}{ Poor communication } & Quality of information & $\begin{array}{l}\text { missing crucial information, forgotten information, improperly } \\
\text { explained tasks, unclearly explained employee responsibilities } \\
\text { for what should be done }\end{array}$ \\
\hline & Miscommunication & $\begin{array}{l}\text { message distortion, different interpretation of the same infor- } \\
\text { mation, failing to listen to the employee's arguments }\end{array}$ \\
\hline
\end{tabular}


Dana EGEROVÁ, Lucie ROTENBORNOVÁ. Towards understanding of workplace conflict: An examination into causes and conflict management strategies

\begin{tabular}{lll}
\hline $\begin{array}{l}\text { Differences in view- } \\
\text { points }\end{array}$ & $\begin{array}{l}\text { Disagreement about work/ } \\
\text { task }\end{array}$ & $\begin{array}{l}\text { different perspectives on the content of the task, disagree- } \\
\text { ment on how a job should be done, different opinions on how } \\
\text { to accomplish the task }\end{array}$ \\
\hline Different expectations & $\begin{array}{l}\text { differences between expectations of the manager and em- } \\
\text { ployee, misunderstanding about what the manager requires } \\
\text { of the employee, setting high expectations for employee's } \\
\text { work despite lack of experience, judging the employee against } \\
\text { unrealistic performance norms }\end{array}$ \\
\hline
\end{tabular}

The findings of the content analysis (Table 2) reveal four approaches (fight, collaboration, avoidance and compromise) to conflict management are used by manager and the five approaches (fight, collaboration, avoidance, adaptation and compromise) by employees. The predominant conflict management style used by the managers is fight, which is used in 26 cases, whereas by employees only in 5 cases. There is a visible disproportion. Thus, we might assume that employees try to avoid confrontation with managers and managers are authoritative and are not open to discussion. The second most frequently used style of managing conflicts is collaboration. Collaboration is used in 9 cases by managers and in 15 cases by employees. As the most effective style the use of collaboration is a good signal. On the other hand, employees tend to use adaptation conflict management styles whereas managers do not use this style to handle conflicts with employees.

Table 2

Conflict Management Styles Manager vs Employee

\begin{tabular}{llccc}
\hline & \multicolumn{4}{c}{ Total } \\
\cline { 2 - 5 } $\begin{array}{l}\text { Conflict Management } \\
\text { style }\end{array}$ & $\begin{array}{c}\text { Absolute number of } \\
\text { used styles }\end{array}$ & $\begin{array}{c}\text { Relative number of } \\
\text { used styles }\end{array}$ & $\begin{array}{c}\text { Absolute number of } \\
\text { used styles }\end{array}$ & $\begin{array}{c}\text { Relative num- } \\
\text { ber of used } \\
\text { styles }\end{array}$ \\
\cline { 2 - 5 } & 8 & 0.08 & 12 & 0.13 \\
\hline Avoidance & 0 & 0.00 & 11 & 0.11 \\
\hline Adaptation & 9 & 0.09 & 15 & 0.16 \\
\hline Collaboration & 4 & 0.04 & 6 & 0.06 \\
\hline Compromise & 26 & 0.27 & 5 & 0.05 \\
\hline Fight & & & & Employee \\
\hline
\end{tabular}

The findings of the content analysis (Table 3) show four common approaches used by both male and female managers to resolve conflicts with employees. These include the fight, collaboration, compromise, and avoidance conflict management styles. The findings also reveal that there are similarities as well as differences in the use of conflict management styles concerning gender. Neither male nor female managers differ in terms of using a dominating style of conflict management. However, it is found that male managers tend to use the collaboration conflict style on a more frequent basis than female managers. The other conflict management styles (avoidance, compromise) show no difference in usage by either of the genders. 
Dana EGEROVÁ, Lucie ROTENBORNOVÁ. Towards understanding of workplace conflict: An examination into causes and conflict management strategies

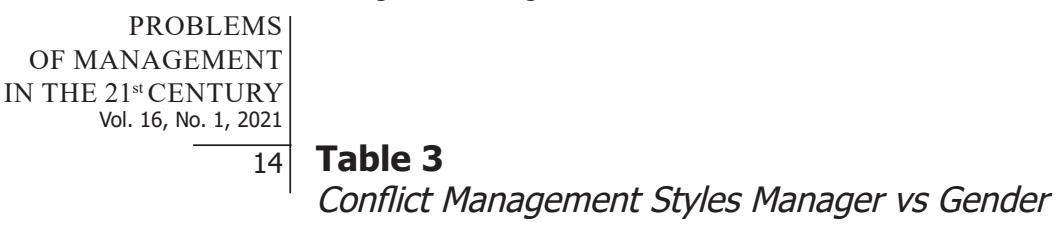

\begin{tabular}{|c|c|c|c|c|}
\hline \multirow{3}{*}{ Managing style } & \multicolumn{4}{|c|}{ Manager } \\
\hline & \multicolumn{2}{|c|}{ Men } & \multicolumn{2}{|c|}{ Women } \\
\hline & $\begin{array}{c}\text { Absolute number of } \\
\text { used styles }\end{array}$ & $\begin{array}{l}\text { Relative number of } \\
\text { used styles }\end{array}$ & $\begin{array}{c}\text { Absolute number of } \\
\text { used styles }\end{array}$ & $\begin{array}{c}\text { Relative number of } \\
\text { used styles }\end{array}$ \\
\hline Avoidance & 5 & 0.11 & 3 & 0.06 \\
\hline Adaptation & 0 & 0.00 & 0 & 0.00 \\
\hline Collaboration & 7 & 0.15 & 2 & 0.04 \\
\hline Compromise & 2 & 0.04 & 2 & 0.04 \\
\hline Fight & 13 & 0.28 & 13 & 0.28 \\
\hline
\end{tabular}

\section{Discussion}

A thematic analysis was carried out to answer the first research question (RQ1). Four general themes related to the causes of conflict between managers and employees emerged from the thematic analysis. Theme one, Poor management, includes selected aspects of managerial qualities, theme two, Manager personality, includes the aspect of manager personality, theme three covers characteristics of communication and theme four, Differences in views, encompasses issues such as disagreement, differences, and misunderstandings. These themes were further broken down into 10 descriptive sub-themes. It is evident that many causes resulted from limited managerial skills like planning skills, organisational skills, time management skills and delegation skills, and interpersonal skills like communication skills. Therefore, it is assumed that organisations should design and implement training for managers to develop and improve the appropriate managerial and interpersonal skills.

A content analysis was carried out to answer RQ2 an RQ3. The analysis indicates that managers prefer to use the fight conflict management style, while employees prefer the collaboration and avoidance conflict management styles. These findings are in line with the study by Slabbert (2019) who found that managers prefer styles based on authority. Some other studies (Mohammed et al. 2008; Gilin Oore et al., 2015) also confirmed that high power individuals differ from low power individuals in handling interpersonal conflict. Furthermore, similarities as well differences were found in the use of conflict management styles as regards gender. There was no gender difference in using dominating conflict management style among managers. However, male managers made greater use of collaboration conflict management style than female managers. These findings are in contrast to those of the previous study by Brewer et al. (2002) who found that female managers preferred to use an integrating conflict management style, not dominating. Also, Rahim and Katz (2019) argue that the use of the conflict management styles has occurred differently by gender. Thus, one possible explanation for our findings may lie in the cultural specifics of the Czech Republic and gender inequality in managerial positions in Czech organisations. Moreover, stereotyping views against women in managerial positions may also be possible factor.

\section{Limitations of the Study}

As with all research studies, this study has some limitations. First of all, the study findings are limited in terms of generalization. This study investigated the causes of conflict and conflict management styles in the context of organisations in the Czech Republic. It is recommended that future research examine such issues in other cultures for generalizability. Moreover, for 
Dana EGEROVÁ, Lucie ROTENBORNOVÁ. Towards understanding of workplace conflict: An examination into causes and conflict management strategies

a deeper understanding of causes and conflict management styles, it is advisable to use both qualitative and quantitative data collection methods.

\section{Conclusions}

The purpose of this study was to investigate the major causes for the occurrence of conflict between managers and employees and the styles used to handle this type of conflict. This study contributes to the existing literature and practice by providing new empirical evidence on workplace conflict. More particularly, the study extends current understanding of how national context and gender influence conflict management style.

Possible practical implication of the study is to guide organisations to better understand how do managers handle the conflict with employees and what are the main causes of the workplace conflict. There are also practical implications for understanding the roles that gender has on conflict management style. These understandings may help organisations to design training programmes for managers to deliver such skills, competencies and strategies which enable them to be able to effectively manage conflicts with employees.

\section{References}

Avgar, A. (2020). Integrating conflict - A proposed framework for the interdisciplinary study of workplace conflict and its management. ILR Review, 73(2), 281-311. 10.1177/0019793919885819

Barki, H., \& Hartwick, J. (2001). Interpersonal conflict and its management in information system development. MIS Quarterly, 25(2), 195-228.

Caputo, A., Ayoko, O. B., \& Amoo, A. (2018). The moderating role of cultural intelligence in the relationship between cultural orientations and conflict management styles. Journal of Business Research, 89, 10-20. https://doi.org/10.1016/j.jbusres.2018.03.042

Barrett, L., Glick, S., \& Clevenger, C. (2011). The process for adopting an energy efficiency code in existing homes: A case study of boulder, Colorado's SmartRegs program. The Journal of Sustainable Real Estate, 3(1), 192-210. https://doi.org/10.1080/10835547.2011.12091819

Blake, R., \& Mouton, J. (1964). The managerial grid: The key to leadership excellence. Gulf Publishing Company.

Bordean, O. N., Rácz, D. S., Ceptureanu S. I., Ceptureanu, E. G., \& Pop, Z. C. (2020). Gender diversity and the choice of conflict management styles in small and medium-sized enterprises. Sustainability Journal, 12(17), Article 7136. https://doi.org/10.3390/su12177136

Braun, V., \& Clarke, V. (2006). Using thematic analysis in psychology. Qualitative Research in Psychology, 3(2), 77-101. https://doi.org/10.1191/1478088706qp063oa

Brewer, N., Mitchell, P., \& Weber, N. (2002). Gender role, organizational status and conflict management styles. International Journal of Conflict Management, 13(1), 78-94. https://doi.org/10.1108/ eb022868

Capozzoli, T. K. (1995). Resolving conflict within teams. Journal for Quality and Participation, 18(7), 2831. search.proquest.com/scholarly-journals/resolving-conflict-within-teams/docview/219150303/ se-2?accountid $=14965$

Chan, J. C. Y., Sit, E. N. M., \& Lau, W. M. (2014). Conflict management styles, emotional intelligence and implicit theories of personality of nursing students: A cross-sectional study. Nurse Education Today, 34(6), 934-939. https://doi.org/10.1016/j.nedt.2013.10.012

Chan, K. W., Huang, X., \& Ng, P. M. (2008). Managers' conflict management styles and employee attitudinal outcomes: The mediating role of trust. Asia Pacific Journal of Management, 25(2), 277-295. https://doi.org/10.1007/s10490-007-9037-4

Cheng, B. H., \& McCarthy, J. M. (2013). Managing work, family, and school roles: Disengagement strategies can help and hinder. Journal of Occupational Health Psychology, 18(3), 241-251. https:// psycnet.apa.org/doi/10.1037/a0032507

Choi, Y. (2013). The influence of conflict management culture on job satisfaction. Social Behavior and Personality, 41(4), 687-692. https://doi.org/10.2224/sbp.2013.41.4.687

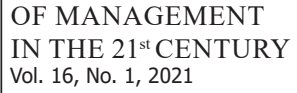


Dana EGEROVÁ, Lucie ROTENBORNOVÁ. Towards understanding of workplace conflict: An examination into causes and conflict management strategies

\section{PROBLEMS \\ OF MANAGEMENT IN THE $21^{\text {st }}$ CENTURY Vol. 16, No. 1, 2021}

16

Cavanagh, S. (1997). Content analysis: concepts, methods and applications. Nurse Researcher, 4(3), 5-16. https://doi.org/10.7748/nr.4.3.5.s2

Danielsson, Ch. B., Bodin, L., Wulff, C., \& Theorell, T. (2015). The relation between office type and workplace conflict: A gender and noise perspective. Journal of Environmental Psychology, 42, 161-171. https://doi.org/10.1016/j.jenvp.2015.04.004

De Dreu, C. K. W. (2011). Conflict at work: Basic principles and applied issues. APA handbook of industrial and organizational psychology, 3, 461-493. https://hdl.handle.net/11245/1.333436

De Raeve, L., Jansen N. W, Van den Brandt, P. A., Vasse R. M, \& Kant, I. (2008). Risk factors for interpersonal conflicts at work. Scandinavian Journal of Work, Environment \& Health, 34(2), 96106. https://doi.org/10.5271/sjweh.1223

Doucet, O., Poitras, J., \& Chenevert, D. (2009). The impacts of leadership on workplace conflicts. International Journal of Conflict Management, 20(4), 340-354. https://doi. org/10.1108/10444060910991057

Gadegaard, Ch. A., Hogh, A., \& Andersen, L. P. (2019). A longitudinal study of the possible escalation of aggressive behaviors - from bullying and conflicts to workplace violence. Is emotional exhaustion a mediator? Work, 64(2), 371-383. https://doi.org/10.3233/WOR-192998

Gilin Oore, D., Leiter, M. P., \& LeBlanc, D. E. (2015). Individual and organizational factors promoting successful responses to workplace conflict. Canadian Psychology/Psychologie canadienne, 56(3), 301-310. https://doi.org/10.1037/cap0000032

Gostin, C., Negoiţă O., \& Purcărea, A. A. (2012). Sources of conflict in industrial enterprises in Romania and ways to improve the situation. Review of International Comparative Management, 13(4), 587-596.

Hsieh, H. F., \& Shannon, S. E. (2005). Three approaches to qualitative content analysis. Qualitative Health Research, 15(9), 1277-1288. https://doi.org/10.1177/1049732305276687

Jehn, K. A. (1997). A qualitative analysis of conflict types and dimensions of organizational groups. Administrative Science Quarterly, 42, 530-557. https://doi.org/10.2307/2393737

Kay, A. A., \& Skarlicki, D. P. (2020). Cultivating a conflict-positive workplace. How mindfulness facilitates constructive conflict management. Organizational Behavior and Human Decision Processes, 159, 8-20. https://doi.org/10.1016/j.obhdp.2020.02.005

Khan, K., Hussainy, S. K., \& Iqbal, Y. (2016). Causes, effects, and remedies in conflict management. The South East Asian Journal of Management, 10(2), 152-172. https://doi.org/10.21002/seam. v10i2.7733

Kim, T. Y., Wang, C., Kondo, M., \& Kim, T. H. (2007). Conflict management styles: The differences among the Chinese, Japanese, and Koreans. International Journal of Conflict Management, 18(1), 23-41. https://doi.org/10.1108/10444060710759309

Lee, D., Huh, Y., \& Reigeluth, C. M. (2015). Collaboration, intragroup conflict, and social skills in projectbased learning. Instructional Science, 43(5), 561-590. https://doi.org/10.1007/s11251-015-9348-7

Lu, L., Zhou, F., \& Leung, K. (2011). Effects of task and relationship conflicts on individual work behaviors. International Journal of Conflict Management, 22(2), 131-150. https://doi. org/10.1108/10444061111126675

Madalina, O. (2016). Conflict Management, a new challenge. Procedia Economics and Finance, 39, 807814. https://doi.org/10.1016/S2212-5671(16)30255-6

Maguire, M., \& Delahunt, B. (2017). Doing a thematic analysis: A practical, step-by-step guide for learning and teaching scholars. AISHE-J: The All Ireland Journal of Teaching and Learning in Higher Education, 9(3), 3351-33514. ojs.aishe.org/index.php/aishe-j/article/view/335

Mohammed, U., White, G. R. T., \& Prabhakar, G. P. (2008). Culture and conflict management style of international project managers. International Journal of Business and Management, 3(5), 3-11.

Moore, C. (1986). The Meditation Process: Practical Strategies for Resolving Conflicts. Josssey-Bass.

Omisore, B. O., \& Abiodun, M. R. (2014). Organizational Conflicts: Causes, Effects and Remedies. International Journal of Academic Research in Economics and Management Sciences, 3(6), 118137. https://doi.org/10.6007/IJAREMS/v3-i6/1351

Patton, Ch. M. (2018). Changes: A Conflict Management Model for Organizational Redesign Efforts. Journal of Conflict Management, 6(1), 26-40. academia.edu/download/57188282/v6n1_Patton. pdf 
Dana EGEROVÁ, Lucie ROTENBORNOVÁ. Towards understanding of workplace conflict: An examination into causes and conflict management strategies

Pelled, L. H., Eisenhardt, K. M., \& Xin, K. R. (1999). Exploring the black box: An analysis of work group diversity, conflict, and performance. Administrative Science Quarterly, 44(1), 1-28. https://doi. org $/ 10.2307 / 2667029$

Rahim, M. A. (1985). A strategy for managing conflict in complex organizations. Asian Pacific Journal of Management, 38(1), 81-89. https://doi.org/10.1177/001872678503800105

Rahim, M. A. (2002). Toward a theory of managing organizational conflict. International Journal of Conflict Management, 13(3), 206-235. https://doi.org/10.2139/ssrn.437684

Rahim, M. A., \& Bonoma, T. V. (1979). Managing organizational conflict: A model for diagnosis and intervention. Psychological Reports, 44(3), 1323-1344. https://doi.org/10.2466/ pr0.1979.44.3c.1323

Rahim, M. A., Magner, N. R., \& Shapiro, D. L. (2000). Do fairness perceptions influence styles of handling conflict with supervisors: What fairness perceptions, precisely? International Journal of Conflict Management, 11, 9-31. https://doi.org/10.1108/eb022833

Rahim, M. A., \& Katz, J. P. (2019). Forty years of conflict: the effects of gender and generation on conflictmanagement strategies. International Journal of Conflict Management, 31(1), 1-16. https://doi. org/10.1108/IJCMA-03-2019-0045

Riaz, M. K., \& Junaid, F. A. (2012). Types, sources, costs \& consequences of workplace conflict. Asian Journal of Management Research, 2(1), 600-611. ssrn.com/abstract=2004302

Slabbert, A. D. (2004). Conflict management styles in traditional organisations. The Social Science Journal, 41(1), 83-92. https://doi.org/10.1016/j.soscij.2003.10.007

Tabassi, A. A., Bryde, D. J., Abdullah, A., \& Argyropoulou, M. (2017). Conflict management style of team leaders in multi-cultural work environment in the construction industry. Procedia Computer Science, 121, 41-46. https://doi.org/10.1016/j.procs.2017.11.007

Tay, A. (2011). Managing generational diversity at the workplace: Expectations and perceptions of different generations of employees. African Journal of Business Management, 5(2), 249-255. https://doi.org/10.5897/AJBM10.335

Tjosvold, D. (2008). The conflict-positive organization: It depends upon us. Journal of Organizational Behavior, 29, 19-28. https://doi.org/10.1002/job.473

Thomas, K. W. (1976). Conflict and conflict management. In: Dunnette, M. D. (Ed.), Handbook of industrial \& organizational psychology (pp. 889-935). Rand McNally.

Van der Zee, K. I., \& Hofhuis, J. (2018). Conflict management styles across cultures. In Y. Y. Kim (Ed.), The international encyclopaedia of intercultural communication. John Wiley \& Sons.

Van Tonder, C., Havenga, W., \& Visagie, J. (2008). The causes of conflict in public and private sector organizations in South Africa. Managing Global Transitions: International Research Journal, 6(4), 373-401. https://ideas.repec.org/a/mgt/youmgt/v6y2008i4p373-401.html

Wright, R. R., Nixon, A. E., Peterson, Z. B., Thompson, S. V., Olson, R., Martin, S., \& Marrott, D. (2017). The workplace interpersonal conflict scale: An alternative in conflict assessment. Psi Chi Journal of Psychological Research, 22, 163-180. https://doi.org/10.24839/2325-7342.JN22.3.163

Zia, Y. A., \& Syed, P. H. (2013). An exploratory study into the causes of conflict and the effect of conflict management style on outcome in a competitive workplace. Journal of Managerial Sciences, 7(2), 299-314. https://www.qurtuba.edu.pk/jms/default_files/JMS/7_2/JMS_July_ December2013_299-315.pdf

\section{OF MANAGEMENT \\ IN THE $21^{\text {st }}$ CENTURY \\ Vol. 16, No. 1, 2021}


Dana EGEROVÁ, Lucie ROTENBORNOVÁ. Towards understanding of workplace conflict: An examination into causes and conflict management strategies

OF MANAGEMENT

IN THE $21^{\text {st }}$ CENTURY

Vol. 16, No. 1, 2021

Accepted: May 10, 2021

Cite as: Egerova, D., \& Rotenbornova, L. (2021). Towards understanding of workplace conflict: An examination into causes and conflict management strategies. Problems of Management in the $21^{\text {st }}$ Century, 16(1), 7-18. https://doi.org/10.33225/pmc/21.16.07

\section{Dana Egerová}

(Corresponding author)
Doc. PaedDr. PhD, Associate Professor, Department of Business Administration and Management, Faculty of Economics,

University of West Bohemia in Pilsen, Univerzitni 8, Pilsen, Czech Republic.

E-mail: egerova@kpm.zcu.cz

Website: https://fek.zcu.cz/en/osobni.php?IDWorker=77\&section=publikace

ORCID: https://orcid.org/0000-0003-1824-9288

Lucie Rotenbornová

Ing., PhD Student in Doctoral Program of Economics and Management, Department of Business Administration and Management, Faculty of Economics, University of West Bohemia in Pilsen, Univerzitní 8,Pilsen, Czech Republic.

E-mail: rotenbor@kpm.zcu.cz

Website: https://fek.zcu.cz/en/osobni.php?IDWorker=423 